\title{
Reforming the National Health Insurance Fund for Better Surgical Care Financing
}

Waruguru Wanjau,

Public Health Consultant

Correspondence to: Dr Waruguru Wanjau, PO Box 60405-00200 Nairobi, Kenya; email: waruguruwanjau@gmail.com

Key words: Global surgery, Health financing, Health systems, Health insurance

Ann Afr Surg. 2019; 16(1):1-3

DOI: http://dx.doi.org/10.4314/aas.v16i1.1
Conflicts of Interest: None

Funding: None

(C) 2019 Author. This work is licensed under the Creative Commons Attribution 4.0 International License.
Health care financing takes several forms. In Kenya, most health care costs are financed as out-of-pocket payments by patients and their families (1). Penetration of private health insurance is low and covers mainly those in formal employment in the major urban centers $(1,2)$. The National Health Insurance Fund (NHIF) is the national state corporation tasked with public health care financing. Membership of NHIF is mandatory for all employees in the public and private sectors but is voluntary for those in the informal sector. By September 2018, at least 25 million Kenyans had NHIF cover, courtesy of 7.6 million principal subscribers (3). In the past, NHIF concentrated on providing ambulance services and paying for bed charges for inpatients. It recently started financing surgical care, previously financed by private insurance or out-ofpocket payments that led to medical impoverishment, increased morbidity and mortality, and poor quality of care $(4,5)$. Financial barriers to care include direct and indirect costs: direct costs relate to care — surgical fees, supplies laboratory tests, drugs, transport, stay at hospital, and food; indirect costs are costs amassed because of the sickness or absence of the patient (6). Without medical cover such as provided by NHIF, a patient must pay for the direct and indirect costs. If the patient is unable to mobilize these resources using outof-pocket payment, access to surgery will be limited or delayed. Unaffordable surgical care leads to late presentation and inability to pay for complete care, including post-operative services that are needed to make a complete recovery (7). Low-income populations are the most affected by the cost of care (8). Inability to pay for surgical care also leads to patients being detained in hospitals as they coalesce social networks to raise the resources required. To protect themselves, private health institutions routinely demand cash deposits or letters of guarantee of payment before providing non-emergency surgical care (9).

NHIF started offering surgical care in 2016 (10). NHIF covers a maximum of USD 5,000 for specialized surgeries, USD 1,300 for major surgeries and USD 500 for minor surgeries (11). Before this, NHIF did not cover surgery costs. In December 2017 NHIF published prospective revised charges for surgical procedures (11). Professional bodies rejected the new charges as they were below the official rates provided by the medical board (12). Under the new rates, a basic surgical procedure such as an incision and drainage is reimbursed at USD 150 while the medical board charges are USD 250-600 for the same procedure (12). NHIF payments for surgical care must balance the need for a decent wage and compensating for investment on the one hand and the sustainability of the fund on the other hand to ensure its sustainability in the long term.

\section{Proposed Reforms}

The principal aim of a restructured and expanded NHIF is to ensure surgery is affordable and accessible especially to the poor who are most affected by the lack of access to surgical care (8). First, NHIF coverage should expand from the current 7.6 million principle subscribers (3) to include every Kenyan adult, to create a bigger pool from which to draw funds for payments. The result would be access to surgical care for a large proportion of the population that previously relied on out-of-pocket payments. The expanded coverage should target the most vulnerable members of society, who will benefit most from being part of the pool. 
Second, NHIF should create a sustainable financing structure to guarantee payments for surgical care. Any inefficiencies will hamper NHIF's ability to finance surgical care over the long term. Ways to increase sustainability include controlling administrative costs (13) and increasing financial efficiency through compensating for early treatment. Third, NHIF should design a system where surgery, even if not life saving, is offered promptly. Early surgical treatment leads to fewer postoperative complications and shorter hospital stays (14). A study by Ikol et al. on pediatric surgery shows that prompt surgical intervention has better outcomes (15). NHIF can also reward less invasive surgical procedures in cases where they would give the same clinical outcomes as more invasive procedures. Minimally invasive surgeries should be encouraged as this leads to shorter operating time, shorter hospital stays and fewer complications (16). A paper by Olwadun et al. in this issue proposes a way of reducing pain during cannulation procedures (17). Were such innovations with proved patient benefits rewarded, surgeons would incorporate them in care provision. Incorporating additional, more cost-efficient approaches to surgical procedures would make financing of surgical services sustainable over the long term on a large scale.

Fourth, NHIF must work with health institutions and the ministry of health to make surgical services more affordable and efficient in the country as a whole. Highvolume cataract centers in India are an example of a context-specific design of surgical provision that has ensured cataract surgery is affordable and accessible (18). These centers have increased the numbers of operations carried out while improving outcomes and controlling costs. Closer home, a paper by Makanga et al. (19) in the current issue of this journal highlights the need for specialist centers to manage urological conditions for better surgical outcomes. A financing model that allows such centers to be created and nurtured should be an integral part of NHIF strategy. NHIF's suggested reform package should therefore combine expanded coverage of the population, sustainable financial structuring of surgical payments, a financial model that rewards more efficient care, and additional context-specific innovations. Reforms should aim to make surgical provision more efficient, leading to affordable and accessible surgical care in Kenya.
Other complementary actions include training more surgeons, health institutions investing more in surgical equipment, and a robust country-wide surgical referral system with dedicated specialized centers for complex surgeries.

\section{Effects of reforms}

With increased demand, high volumes and assured payment from NHIF, health institutions will invest in surgical infrastructure (20). Surgical equipment is a costly capital investment (21) and without an assurance on return on investment through regular patients and adequate numbers, institutions are unlikely to invest in equipment.

The demand for surgeons will increase. Increased access to surgical care will likely result in a gap between the available number of surgeons and increased demand. Affordable and dependable access to surgical services will lead to reduced financial catastrophies, predictable ways for paying for surgical care, and timely and adequate care as patients seek care at the appropriate time and before seeking alternative but less adequate treatment (22).

Increasing access to surgical care will address an emergent need in the country for conditions such as cancer (23) that are becoming more prevalent in Kenya and require surgical intervention.

\section{Outcomes of the proposed reforms}

Several positive outcomes are anticipated. The suggested reforms will involve surgery-specific changes, but most will be broader and will shore up the NHIF as a whole. In providing surgical care, NHIF will emerge as a sustainable and robust institution. Other options for increasing financing for surgical care, such as asking for government funding earmarked for surgery, would be a silo approach that will not improve a central entity such as NHIF.

To provide surgical care, other hospital services such as blood transfusion, laboratory services and radiology must be available. These services will benefit the health institutions beyond the surgical unit.

Some negative outcomes are expected from these reforms. Increased demand and reduced supply could easily lead to system delays in gaining access to care. Patients will be on waiting lists as the available resources funded by NHIF can only provide for a certain number 
of surgeries at a given time (24). Waiting lists would most likely affect elective surgeries (24).

\section{References}

1. Barasa EW, Maina T, Ravishankar N. Assessing the impoverishing effects and factors associated with the incidence of catastrophic health care payments in Kenya. Int J for Equity in Health. 2017; 16(1):31.

2. Amu H, Dickson KS, Kumi-Kyereme A, Darteh EKM. Understanding variations in health insurance coverage in Ghana, Kenya, Nigeria, and Tanzania: Evidence from demographic and health surveys. PloS One. 2018; 13(8):e0201833.

3. Kajilwa G. The strain patients without insurance put on hospital resources. 6 September 2018. Available from: https://www.standardmedia.co.ke/article/2001294741/ the-strain-patients-without-insurance-put-on-hospitalresources. Accessed 14 January 2019.

4. Shrime MG, Dare AJ, Alkire BC, O’Neill K, Meara JG. Catastrophic expenditure to pay for surgery worldwide: A modeling study. The Lancet Global Health. 2015; 3:S44.

5. Alkire BC, Raykar NP, Shrime MG, et al. Global access to surgical care: A modeling study. The Lancet Global Health. 2015; 3(6):e323.

6. Grimes CE, Bowman KG, Dodgion CM, Lavy CB. Systematic review of barriers to surgical care in lowincome and middle-income countries. World J Surg. 2011; 35(5):941-50.

7. Li X, Veltre DR, Cusano A, et al. Insurance status affects postoperative morbidity and complication rate after shoulder arthroplasty. J of Shoulder and Elbow Surg. 2017; 26(8):1423-31.

8. Zafar SN, Fatmi Z, Iqbal A, Channa R, Haider AH. Disparities in access to surgical care within a lower income country: An alarming inequity. World J Surg. 2013; 37(7):1470-77.

9. Macharia WM, Njeru EK, Muli-Musiime F, Nantulya $\mathrm{V}$. Severe road traffic injuries in Kenya, quality of care and access. African Health Sciences. 2009; 9(2).

10. Kiarie M. NHIF surgery cover set to ease members' healthcare burden. August 2016. Available from: https://www.businessdailyafrica.com/NHIF-announcessurgery-benefits-for-members/539546-3361794hoa $7 \mathrm{k} 0 \mathrm{z} /$. Accessed 22 December 2017.
11. NHIF. Suggested NHIF surgical rates 2017\&nbsp. 2017.

12. Kenya Medical Practitioners and Dentists Board. The medical practitioners and dentists (professional fees) rules, 2016. Available from: http://medicalboard. co.ke/resources/Medical_and_Dental_Professional Fees 2016.pdf.

13. Berwick DM, Hackbarth AD. Eliminating waste in US health care. JAMA. 2012; 307(14):1513-16.

14. Siegmeth AW, Gurusamy K, Parker MJ. Delay to surgery prolongs hospital stay in patients with fractures of the proximal femur. Bone \& Joint J. 2005; 87(8):1123-26

15. Ikol KM, Saula PW, Gisore P, et al. Outcomes of neonates requiring surgical interventions in Eldoret. Ann Afr Surg. 2019; 16 (1):21-26.

16. Wilmore DW, Koehler H. Recent advances: Management of patients in fast track surgery. BMJ. 2001; 322(7284):473

17. Oluwadun OB, Adekola OO, Olufemi IO, et al. EMLA cream vs. $10 \%$ Lidocaine cream for attenuating venous cannulation pain - A clinical trial. Ann Afr Surg. 2019; 16(1):4-10.

18. Yorston D. High-volume surgery in developing countries. Eye. 2005; 19:1083.

19. Makanga W, Agbo CA. One-stage urethroplasty for strictures at a rural hospital. Ann Afr Surg. 2019; 16(1):16-20.

20. Ologunde R, Holmer H. Surgical care: Addressing the barriers to access in low-income countries. World J Surg. 2014; 38(5):1243-44.

21. Mir SA, Cadeddu JA, Sleeper JP, Lotan Y. Cost comparison of robotic, laparoscopic, and open partial nephrectomy. J Endourology. 2011; 25(3):447-453.

22. Kukla M, McKay N, Rheingans R, et al. The effect of costs on Kenyan households' demand for medical care: Why time and distance matter. Health Policy Plan. 2017; 32(10):1397-1406.

23. White RE, Parker RK. Cancer in Kenya: Outlook and perspectives. Ann Afr Surg. 2018; 15(4):1.

24. Martin RM, Sterne JA, Gunnell D, Ebrahim S, Smith GD, Frankel S. NHS waiting lists and evidence of national or local failure: Analysis of health service data. BMJ. 2003; 326(7382):188. 